\title{
Exploration on Culture Characteristics of Japanese Language
}

\author{
Rui Gao ${ }^{1}$ \\ ${ }^{1}$ Xi'an University, Xi'an, 710065
}

KEYWORDS: Japanese Culture; Japanese Language; Teaching Reform

\begin{abstract}
Japanese as the language used in the Japanese national independence, in its long course of development, has been a huge influence in the early years as the center of Chinese Han culture, but also by the impact of modern English as the center of Western culture. Despite these effects and impact are enormous and profound, but in Japanese language and culture, but to save their own distinctive national characteristics. The following will be the main features of Japanese language and culture to make an initial discussed.
\end{abstract}

\section{Introduction}

There are a lot of text on the current world, but there are a lot of languages, but in the final analysis, the current text of the world can be divided into two categories, one is phonetic, these words primarily to the definition of the word through text pronunciation , there is a class ideogram, these words first thing is represented by a meaning, definition of the final text, such as "\# characters as ideographic characters in the world is currently represented, now widely used in the world of Chinese characters China is not the only country, China Japan's neighbors are also using Chinese characters. Japanese ideographic characters using only text, but also the use of phonetic kana, the ability to represent the current mix of different languages, Japanese is one of the First, while this is a major feature of Japanese.

\section{A Traditional "Harmony" Ideal}

In the process of the development of the Japanese economy, in order to coordinate the internal contradictions and conflicts between people, the Japanese began to pay attention to the problem to build good relations. This is reflected in language and culture, that is, they are more inclined to use the kind of subtle and tactful expression. If a personal and collective thought made some contrary things, other people will be ridiculed or even rejection. Thus, the Japanese attach great importance to relations with the people around them, and sometimes other people's point of view is more important than their own. They lead this ethical standards, it has formed an emphasis on individual and collective relations of good atmosphere, and thus the language in showing a more modest trend.

\section{The Expression Characteristics of Japanese Language}

The expression characteristics of the Japanese language and culture is actually a concentrated expression of the Japanese mindset, they also reflect fundamental character habits. Japanese learners only a good understanding of Japanese language and Japanese culture, it could really learn and make good use of Japanese. To analyze the existing situation to the Japanese language and culture of the most notable features is its expression of ambiguity, which is the Japanese restraint 
implicit attitudes and behavior decisions. Next, we will analyze the specific features of ambiguous language and culture at Japan's performance in several aspects.

Strong internal and external awareness. Japan, the nation has a relatively strong sense of inside and outside, so they rarely use your language, my vocabulary to express this, because they think it's a bit rusty and rigid pronoun. In other words, the Japanese language will often use some inside and outside the clear wording or honorific words to express you my points. Sometimes, the Japanese will be through the offering and accepting of my sentence to express your points. However, the gap between the language of which China is large, because we have no corresponding Chinese expression, of course, there is no corresponding word. This is mainly because the language huge cultural differences between China and Japan caused by the differential expression. Of course, there are a lot of Japanese weather, courtesy of greetings, which in Chinese is not a language of expression; The euphemistic language. One of the most significant feature is that often there is a Japanese euphemism polite language of feeling, it is mainly because the Japanese have been "and" mode of thinking and the results of the "heart to heart" a tremendous impact caused by consciousness.

Thus, when the Japanese get along with people, they often want to maintain a healthy heart, including interaction with others as much as possible to establish harmony between a pleasant atmosphere along a Kind, thereby maintaining a relatively pleasant state of mind. This makes the Japanese language to communicate during the time, often taking fully into account each other's feelings, as much as possible to use some feel the other side of the goodwill of the language of expression, even knowing that either meet the aspirations of the other, but still want to use to make may not cause the other party discontent language expression. In view of this, in Japanese, there are many clever and politely refused to answer, etc., so that the other side was not so emotional rejection and anger. This is because the Japanese one is the lack of awareness and the concept of opposition or not, they do not like it or not between the two is to make certain choices. When dealing with people they will often try not to hurt each other's feelings. Thus, they communicate in the language, it will not be directly applied for or against such a direct way of stimulating language. They would when dealing with people, and closely observe each other's behavior changes. This is the Japanese for the sake of others ideological and cultural expression. When we contact with the Japanese, it must be noted euphemism characteristics they express aspects of this language and culture, so that it can really understand their true intentions, thus contributing to the smooth exchange.

Japanese ambiguity is also reflected in some aspects ambivalent language expression. Verbal communication during the time they will often take an indirect way of expression and lack of clarity of words to express a vague meaning. Hearer is difficult to accurately grasp their true meaning. For example, some Japanese words can express different meanings in different contexts. This requires the listener according to the specific locale to accurately grasp the speaker's meaning. That is why the Japanese often and at some time after the number with some probability numeral reason, they will try to make the expression obscured; widespread use honorific. Japanese honorifics is more special language expression, it often refers to the speaker based on the relationship between the listener like a language to express their own expression of respect for each other. Should, the Japanese honorific is a very important means of expression, is an important manifestation of the Japanese way of thinking and communicative way, it is a concentrated reflection of Japanese society and culture of a superior-subordinate relationship; expression.

Japanese will encounter some of the rejected communicative situation. However, the Japanese are not used to directly reject others, so they often omit the use of the way to avoid embarrassment. 
For example, in Japanese, personal pronouns and sentence elements omitted is often synonymous not explicitly rejected. In the first meeting, when the Japanese will often say, "Nice to meet you", but it will omit the "thanking you in advance", which is logical because the Japanese already will naturally add the meaning of. In addition, when the Japanese when communicating, have been known for some information, they will be omitted. Although the Japanese expression for this language for granted, however, Chinese or other languages and cultural backgrounds, may not be able to accurately understand its true meaning; multiple.

Italian expression. First, the Japanese have a term of two minds expression. This means that the Japanese have the same vocabulary, but it may have different meanings, or even to express a contrary meaning. This requires Japanese learners based on the specific context to make the right judgments, otherwise, it will cause errors and even verbal communication misunderstanding. We can speak human behavior and facial expressions to analyze the true meaning of words. Although the Japanese want to give each other room for a kind of communion, but actually increased the difficulty of communication. We have in-depth experience of its euphemistic language to express indirect manner, and accurately grasp the margin on its language, to really try to figure out the speaker's true intentions. Secondly, there are some Japanese needing to grasp the implication. The Japanese exchanges, often pay attention to emotional communication, and therefore, even if the other party does not agree with the views expressed will be tactful, which need each other to accurately understand the speaker's implication. This is the Japanese polite, educated one performance, they embodied empathy positions; expression.

Negative speculation. Come and make the Japanese when invited, but will use negative language expression. It is thought that if they were someone else's denial does not mean very embarrassing. This is in fact the Japanese negative form of language to express a positive meaning. This is the Japanese for their own burning our bridges, but also taking into account respect for others, it is a Japanese expression in a more rounded form of language. Moreover, the Japanese language but also in the form of a speculation to express humility, which they attach importance to the people around them feel good quality.

\section{The Source of Characteristics of Japanese Language and Culture}

Ambiguous way of speaking is actually a Japanese in the process of communication "and the perfect embodiment of the spirit. Whether in life or in social relationships, whether it is for younger elders, superiors will exchange subordinates or colleagues strongly give each other to avoid direct damage, avoid embarrass the other side. in Japanese with each other when the exchange will tend to view each other in the first place, largely concerned about each other's thinking and the other's point of view, and not in exchange when stiffly rejected each other, provoke each other and not say the words, feeling each other's meaning and true intentions of the other side is a typical Japanese culture from demeanor. Japanese way conversation with our ancient way people talk very similar often by passing between the heart and the heart to talk, in the course of conversation, the Japanese will always pay attention to every detail \& other facial expression and every word in the wording, the other through conversation and demeanor Get itself favorable thing, the Japanese will be such exchanges is called to mind and heart, by means of verbal exchanges make their own to take the hint. the Japanese often and as long as the exchange that the two sides have the same cultural background and foundation of life, even if the thing metaphorical expression, and the other can understand its meaning through the meaning of words, in such a culture based on the use of only the expression is omitted, which is the formation of cultural identity of Japan one of the reasons. in addition, there are many reason, Japan, as an island, the resources are very poor, led to the Japanese 
culture is determined by its restrictions and geographical factors. Therefore, the Japanese language will appear unknowingly overdraft phenomenon, so in Japanese culture tends to absorb other cultural country, and to organize, to form their cultural characteristics.

\section{Conclusion}

In summary, the form of Japanese language and culture has a variety of expression, but a variety of psychological factors resulting in specific factors are the main factors of the Japanese language and cultural characteristics, as well as language is the carrier of culture, culture is the transfer mode .

\section{REFERENCE:}

[1] Fan Dongni. Japanese foreign words in the Japanese language and cultural characteristics [J]. Liaoning Teachers College: Social Sciences, 2015 (1): 14-15.

[2] Zhu Daming. Japanese language and cultural characteristics Revisited [J]. PLA Studies University, 1996 (2): 50-57.

[3] Zhu Daming Japanese language and cultural characteristics Fourth Exploration [J]. Foreign Language Research (Heilongjiang University), 1998 (1): 66-67,55.

[4] Zhao Hua visited Japan and cultural development, the formation of the Japanese language analysis [J]. exam Week, 2015 (43): 21-22.

[5] Mao Fenglin Japanese expression characteristics and pragmatic relations with Context [J]. Japanese Study and Research, 2008 (2): 12-17. 